\title{
Monetary Policy and Commodity Futures
}

\author{
Michelle T. Armesto and William T. Gavin
}

\begin{abstract}
This paper constructs daily measures of the real interest rate and expected inflation using commodity futures prices and the term structure of Treasury yields. We find that commodity futures markets respond to surprise increases in the federal funds rate target by raising the inflation rate expected over the next 3 to 9 months. There is no evidence that the real interest rate responds to surprises in the federal funds target. The data from the commodity futures markets are highly volatile; we show that one can substantially reduce the noise using limited information estimators such as the median change. Nevertheless, the basket of commodities actually traded daily is quite narrow and we do not know whether our observable rates are closely connected to the unobservable inflation and real rates that affect economywide consumption and investment decisions.
\end{abstract}

Federal Reserve Bank of St. Louis Review, May/June 2005, 87(3), pp. 395-405.

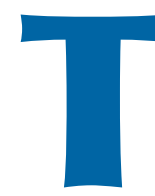

he Federal Reserve targets the interest rate on federal funds to implement monetary policy. The interest rate is composed of two unobservable factors, the real interest rate and a premium for expected inflation, which are important for understanding the appropriate setting of the target. Knowing how these two factors change in response to changes in the target is also important for implementing monetary policy. Empirical evidence about the level and changes in these factors is complicated by the lack of direct observations on them. ${ }^{1}$ In this paper, we extract measures of the interest rate and expected inflation from commodity futures prices and use these measures to examine how interest rates and expected inflation respond to monetary policy shocks. Throughout this paper we use the terms inflation and real interest rate interchangeably with commodity price inflation and commodity own rate. Whether our results have important implications for monetary policy

1 Clark and Kozicki (2004) survey the literature and show that there is a great deal of uncertainty in real-time estimates of the equilibrium real interest rate. depends on how closely our measures derived from commodity markets are connected to the inflation rates and real interest rates that matter for consumption and investment decisions.

Since 1997, the United States has issued inflation-indexed bonds. By extracting observations about expected inflation and the real interest rate in this market, several studies have found evidence about how real and nominal interest rates react to monetary policy surprises. For example, Gürkaynak, Sack, and Swanson (2003) show that the implied forward 1-year rate at the 9-year horizon responds significantly to a surprise in the federal funds market. They find that the surprise is contained in the expected inflation premium and not in the implied forward real rate.

Kliesen and Schmid find a similar result for the 10-year rate (2004a) and for the real rate (2004b), but in their papers, it is not clear what part of the 10-year term structure is responding to the news. There is one drawback to these measures of the real rate and the expected inflation rate: The maturity of these investments is measured in years, and the analysis does not reveal information about the response of the real interest rate 
or expected inflation in the short end of the term structure.

Cornell and French (1986) provide indirect observations on the short end of the term structure by using a measure of the real interest rate extracted from commodity futures prices. They use this measure to gauge the reaction of real interest rates and expected inflation to surprises in the weekly money supply announcements between October 6, 1977, and March 23, 1984. Their results were somewhat surprising: They found that it was expected inflation in commodity prices and not real returns that went up when there was an unexpected increase in the money supply. These results were obtained using data after October 6, 1979, an era in which the Treasury bill (T-bill) rate responded strongly and positively to surprise increases in the money supply. Before this result, previous authors concluded that these increases in the T-bill rate were due to rising real interest rates-a liquidity effect, perhaps associated with sticky prices (Roley and Walsh, 1985) or with rationing in the market for borrowed reserves (Gavin and Karamouzis, 1985).

We find results reminiscent of Cornell and French (1986). We estimate the market's reaction to surprises in the Fed's interest rate target. The next few sections explain how the market variables and the policy target surprises are constructed. In the results section, we show that expected inflation responds positively and significantly to surprises in the federal funds rate target in the horizon from 0 to 9 months. We also show that there is no significant response of real interest rates out to a year on the term structure. Although the real interest rate and expected inflation rate constructed using averages from commodity futures data are highly volatile, limited information estimates such as the median change can substantially reduce the noise in such measures.

\section{MEASURING THE REAL INTEREST RATE}

The real own rate of return for each commodity is implied by the term structure of interest rates in the market for T-bills and the term structure of futures prices in the commodity futures market. ${ }^{2}$ Suppose that there is a fixed bundle of consumption goods, $Q$, that is traded in futures markets in every period. The real interest rate in terms of $Q$ from time $t$ to time $t+k$ is defined as the rate at which the household can contract today to exchange units of $Q$ at time $t$ for units of $Q$ at $t+k$. The cost of bundle $Q$ at time $t$ is $S_{t}$ defined as

$$
S_{t}=\sum_{i=1}^{N} q_{i} S_{t}^{i}
$$

where there are $N$ commodities indexed by $i, q_{i}$ is the amount of good $i$ in the bundle, and $S_{t}^{i}$ is the price of good $i$ at time $t$.

If there were complete futures markets for all the goods in $Q$, then the household could contract to buy the bundle at time $t$ for consumption at time $t+k$. The cost of the bundle is given by the futures price, ${ }_{t} F_{t+k}$, which is a sum of individual futures prices

$$
{ }_{t} F_{t+k}=\sum_{i=1}^{N} q_{i} F_{t+k}^{i}
$$

where ${ }_{t} F_{t+k}^{i}$ is the futures price of good $i$ at time $t$ for delivery $k$ periods ahead. At time $t$ the household can purchase discount bonds that mature at $t+k$ and use the funds to buy the bundle of commodities, $Q$. The price of the bundle at time $t$ then is ${ }_{t} F_{t+k} B_{t+k}$, where $B_{t} B_{t+k}$ is the price of a discount bond that pays one dollar at $t+k$. The gross interest rate from $t$ to $t+k, 1+{ }_{t} r_{t+k}$, is the ratio of the cost of the bundle today to the cost of the future bundle today:

$$
1+{ }_{t} r_{t+k}=\frac{S_{t}}{{ }_{t} F_{t+k} B_{t+k}} .
$$

Cornell and French (1986) show that this real rate is an expenditure-weighted average of the commodity own rates. ${ }^{3}$

In the empirical application described here

\footnotetext{
2 This section draws heavily from Cornell and French (1986).

3 They assume that the commodity bundle includes all goods traded in the market, so the commodity own rate is the relevant real interest rate. To the extent that some goods are excluded, this real rate may differ from the real rate that affects consumer and business spending decisions. Gorton and Rouwenhorst (2004) show systematic differences between returns in commodity futures and bonds at lower frequencies.
} 
later, date $t$ is the day of the policy action. We use the maturing contract as the spot price to ensure that the spot and futures prices refer to exactly the same item being traded. However, if the maturing contract does not mature within the next 46 days, we omit this spot price from our data set. We construct a set of futures prices for commodity contracts maturing at $k$ days for $k=\{90,180,270$, $360\}$. We then calculate the implied forward own rates. When there are no spot prices available, we are able to calculate the implied forward rates because the spot price drops out of the formula. For example, the own rate over the horizon $t+k$ +90 is given by

$$
1+{ }_{t} r_{t+k+90}=\frac{S_{t}}{{ }_{t} F_{t+k+90}{ }_{t} B_{t+k+90}},
$$

and the implied forward rate from $t+k$ to $t+k+90$ is given by

$$
1+{ }_{t+k} r_{t+k+90}=\frac{{ }_{t} F_{t+k}{ }_{t} B_{t+k}}{{ }_{t} F_{t+k+90}{ }_{t} B_{t+k+90}},
$$

where the implied forward rate is the rate at which one can trade the bundle at $t+k$ for the bundle at $t+k+90$.

\section{MEASURING THE EXPECTED INFLATION RATE}

The expected inflation rate in commodities is calculated from the relative bases in commodity markets. The basis is defined as the difference between the spot price and the futures price of a commodity. Over the horizon $t+k+90$, this expected inflation rate in a given commodity, then, is given as the relative basis, ${ }_{t} b_{t+k+90}$, which is just the basis divided by the spot price:

$$
{ }_{t} b_{t+k+90}=\frac{{ }_{t} F_{t+k+90}-S_{t}}{S_{t}}
$$

or, in gross terms,

$$
1+{ }_{t} b_{t+k+90}=\frac{{ }_{t} F_{t+k+90}}{S_{t}} .
$$

We aggregate relative bases across the commodity bundle to get the expected inflation rate for commodities. We calculate the term structure of implied expected inflation rates in the same manner as we calculated the implied own rates. For example, the implied forward expected inflation rate from $t+k$ to $t+k+90$ is given by

$$
1+{ }_{t+k} b_{t+k+90}=\frac{{ }_{t} F_{t+k+90}}{{ }_{t} F_{t+k}},
$$

where the implied forward expected inflation rate is the 3-month inflation rate expected for the period $t+k$ through $t+k+90$. Note that this calculation includes the basis risk-that is, a premium for bearing risk that the actual price in the future will be different from today's futures price. Our web-based data appendix (which appears with this article at http://research.stlouisfed.org/publications/review/) includes summary statistics for the changes in commodity own rates and commodity bases around Fed policy surprises.

\section{THE COMMODITY DATA}

The 34 commodities included in our futures market data are listed in Table $1 .{ }^{4}$ The commodities were traded on several different North American exchanges: the Coffee Sugar Cocoa Exchange, the Chicago Board of Trade, the Chicago Mercantile Exchange, the New York Mercantile Exchange, the Kansas City Board of Trade, the Minneapolis Grain Exchange, the New York Cotton Exchange, and the Winnipeg Stock Exchange. On average, commodity prices fell $2 / 3$ of a percentage point per year during our sample period. But there was substantial dispersion across commodities. At the high end, palladium was an outlier, rising on average 11.93 percent per year. At the low end, orange juice fell on average 5.79 percent per year. There were contracts expiring for all of the commodities except high-grade copper throughout our full sample period. The first futures contract in high-grade copper expired in 1989.

\footnotetext{
4 We chose not to update the data set to include the post-2001 data. Our data, which come directly from the market electronic feeds, were purchased from the Institute for Financial Markets in August 2002. This company, sold to MJK Associates, no longer provides data in the format used in 2002.
} 
Table 1

Commodities Included in the Sample

\begin{tabular}{|c|c|c|c|c|}
\hline Commodity & Traded in market & $\begin{array}{l}\text { No. of contracts } \\
\text { expiring in } 1988\end{array}$ & $\begin{array}{l}\text { No. of contracts } \\
\text { expiring in } 2001\end{array}$ & $\begin{array}{c}\text { Average } \\
\text { inflation rate }\end{array}$ \\
\hline Coffee (KC) & CSCE & 5 & 5 & $-5.64 \%$ \\
\hline Corn $(\mathrm{CN})$ & CBT & 5 & 7 & $-1.80 \%$ \\
\hline Feeder cattle (FC) & CME & 8 & 8 & $0.22 \%$ \\
\hline Gold (GC) & NYMEX & 6 & 12 & $-3.31 \%$ \\
\hline High-grade copper (HG) & NYMEX & 0 & 12 & $-5.01 \%$ \\
\hline Live hogs (LH) & CME & 7 & 7 & $3.53 \%$ \\
\hline Live cattle (LC) & CME & 6 & 6 & $-0.20 \%$ \\
\hline Oats (OA) & $\mathrm{CBT}$ & 5 & 5 & $-4.71 \%$ \\
\hline Platinum (PL) & NYMEX & 4 & 4 & $0.26 \%$ \\
\hline Pork bellies (PB) & CME & 5 & 5 & $5.46 \%$ \\
\hline Silver (SI) & NYMEX & 6 & 12 & $-2.61 \%$ \\
\hline Soybeans (SY) & CBT & 7 & 7 & $-4.36 \%$ \\
\hline Soybean meal (SM) & CBT & 8 & 8 & $-3.64 \%$ \\
\hline Soybean oil (BO) & CBT & 8 & 8 & $-2.62 \%$ \\
\hline Wheat (WC) & CBT & 5 & 5 & $-3.49 \%$ \\
\hline Silver 1000 oz (AG) & CBT & 6 & 12 & $-2.67 \%$ \\
\hline Gold - kilo (KI) & $\mathrm{CBT}$ & 6 & 6 & $-3.64 \%$ \\
\hline Sugar (SB) & CSCE & 5 & 4 & $-0.20 \%$ \\
\hline Wheat (KW) & KCBT & 5 & 5 & $-1.56 \%$ \\
\hline Wheat - white (MW) & MGE & 5 & 5 & $-1.20 \%$ \\
\hline Cotton $(\mathrm{CT})$ & NYCE & 5 & 5 & $-1.60 \%$ \\
\hline Crude oil - light (CL) & NYMEX & 12 & 12 & $4.28 \%$ \\
\hline Heating oil $(\mathrm{HO})$ & NYMEX & 12 & 12 & $2.93 \%$ \\
\hline Liquid propane (PN) & NYMEX & 12 & 12 & $6.85 \%$ \\
\hline Palladium (PA) & NYMEX & 4 & 4 & $11.93 \%$ \\
\hline Unleaded gasoline (HU) & NYMEX & 12 & 12 & $6.45 \%$ \\
\hline Cocoa $(\mathrm{CC})$ & CSCE & 5 & 5 & $-3.15 \%$ \\
\hline Orange juice (JO) & NYCE & 6 & 6 & $-5.79 \%$ \\
\hline Rice (NR) & $\mathrm{CBT}$ & 5 & 6 & $-1.44 \%$ \\
\hline Lumber (LB) & CME & 6 & 6 & $2.85 \%$ \\
\hline Flax seed (WF) & WINN & 3 & 5 & $-2.76 \%$ \\
\hline Oats (WO) & WINN & 5 & 5 & $-3.50 \%$ \\
\hline Rapeseed (WP) & WINN & 5 & 7 & $-1.49 \%$ \\
\hline Wheat (WW) & WINN & 5 & 5 & $0.04 \%$ \\
\hline
\end{tabular}

NOTE: CSCE, Coffee Sugar Cocoa Exchange; CBT, Chicago Board of Trade; CME, Chicago Mercantile Exchange; NYMEX, New York Mercantile Exchange; KCBT, Kansas City Board of Trade; MGE, Minneapolis Grain Exchange; NYCE, New York Cotton Exchange; WINN, Winnipeg Stock Exchange. 
The initial format of the data consisted of hundreds of individual files, each containing detailed information about a particular commodity futures contract: the underlying commodity; the month and year the contract expired; and the open, close, high, and low prices for each day that the contract was traded. From these files we construct time series of prices for all 34 commodities for days surrounding our measure of monetary policy surprises. The difference between the close price on the day before the Fed's target change and the opening price on the day after the Fed's target change is used to gauge how the market responds to incoming information about monetary policy. ${ }^{5}$ A term structure of prices for each commodity is constructed using contracts with different expiration dates.

The number and length of contracts varies across commodities. The most frequently traded commodities are crude oil, heating oil, liquid propane, and unleaded gasoline, which have contracts expiring in every month. Others were not as active. Contracts for platinum and palladium expire just four times per year. Additionally, the length of the individual contracts varied. For example, the majority of coffee's commodity contracts (92 percent) were traded for longer than one year, while no contracts were traded for less than one month. Conversely, the majority of flax seed contracts traded within the horizon of 6 to 12 months (86 percent), whereas only two contracts (3 percent) traded for longer than one year. Silver (1000 oz) had the largest quantity of contracts that traded for less than one month (7 percent).

There would be many gaps in the time series of term structures if we insisted on using only those contracts that expired exactly $3,6,9$, and 12 months from the day of a monetary policy surprise. We use simple decision rules to construct a term structure of prices that approximates prices at spot, 3-month, 6-month, 9-month, and 12-month horizons. First, we looked at all contracts that had been traded in the individual commodity on the

\footnotetext{
5 Note that, since 1994, the announcements of policy changes are scheduled for release at a preannounced time, so that today one could use higher-frequency data and a much smaller window in which to measure market reaction. But in the period before 1994, we do not have good information about when, during the day, the market learned about the policy change.
}

day before and day after a monetary policy surprise. We used the maturing contract as a measure of the spot price to ensure that the underlying commodity for the spot price was the same as for the futures contracts. A contract price was considered to be the spot price if the contract had less than 47 days from the day before the policy surprise until expiration. For the 3-month price, a contract was selected if it had between 48 and 137 days until expiration. Similar windows were constructed for the 6-, 9-, and 12-month horizons. For the 6-month futures price, the window was from 138 to 227 days. The 9-month window was from 228 to 317 days, and the 12-month window was from 318 to 417 days until expiration.

When there is no contract expiring in a window, then we have no observation for that commodity. When there was more than one contract within the window, we chose the one closest to our ideal term structure; that is, for the spot price, we choose the contract with the closest date to expiration. For all others, the preference was for the center of the window. For example, for the 3month futures price for the day after the Fed's policy change, the contract used to represent the 3-month futures price was the one closest to expiring in 90 days. This selection method is similar for the 6-, 9-, and 12-month futures price. These prices were then used to compute our own rates and bases.

\section{WHAT IS A SURPRISE IN THE FEDERAL FUNDS RATE TARGET?}

We use measures of the monetary policy surprise as constructed by Poole, Rasche, and Thornton (2002). Data from the federal funds futures market is used to measure the expected change in monetary policy. The federal funds futures market is a bet on the average effective federal funds rate for the month in which the contract matures; as a result, it is an estimate of market expectations about the average level of the federal funds rate for that month.

The Chicago Board of Trade began trading federal funds futures contracts in October 1988. When this trading began, the Federal Reserve was using a target or "expected trading level" for the 
federal funds rate as a guide for daily open market operations, but it did not announce its short-run targets until 1994. Poole, Rasche, and Thornton describe the history of Fed policy changes as embodied in a target or expected trading level for the federal funds rate for the pre-1994 period; they also show that the market often could see when the Fed's target was changed. Fed policy has been transparent since 1994, but what the market expects as it compares with what actually occurs is still a relevant issue.

The unexpected component of the Fed's actions is implied by the change in the futures market price from the day before to the day after the policy change. Suppose $f f f_{t}^{h}$ denotes the rate on the $h$-month federal funds futures contract on day $t$. This rate is equivalent to the sum of the expectation on day $t$ of the federal funds rate on each day of the month, averaged across the length of the month. Hence,

$$
\int f f_{t}^{h}=1 / m \sum_{i=1}^{m} E_{t}\left(f f_{i}^{h}\right),
$$

where $f f_{i}^{h}$ denotes the federal funds rate on day $i$ of the $h$ th month, $E_{t}$ denotes the expectation on day $t$, and $m$ denotes the number of days in the month.

Next, consider if the Fed successfully targets the federal funds rate, so that the actual federal funds rate is equal to the target plus an i.i.d. mean zero error term:

$$
f f_{t}=f f_{i}^{*}+\eta_{t} .
$$

The expectation of the future federal funds rate depends on expectations about the policy target. The surprise in the federal funds market is calculated as the change in the federal funds futures price following a monetary policy action. Substituting the federal funds target into the formula for the federal funds futures rate and taking the difference yields

$$
\Delta f f f_{t}^{h}=1 / m \sum_{i=1}^{m}\left[E_{t}\left(f f_{i}^{*} h\right)-E_{t-1}\left(f f_{i}^{*} h\right)\right] .
$$

If the policy change was perfectly anticipated, then there will be no change in the futures price.

Before 1994, whether or not the market was aware of the Fed's actions is an issue. Poole, Rasche, and Thornton (2002) use reports in the financial press to distinguish between days when the market was aware and days when they were unaware that policy had changed. We examine only days in which they find that the market was aware that policy had changed.

\section{MEASURING THE MARKET RESPONSE}

The market response following a policy action is measured as the change in the own rate or expected inflation calculated using the closing price from the day before the policy change to the opening price on the day after. The expiration date is fixed, so the actual horizon gets 2 days shorter during the interval of the policy change. The change in the 3-month-ahead own rate for a given commodity is $\Delta_{0} r_{90, t}^{i}={ }_{0} r_{90, t+1}^{i}-{ }_{0} r_{90, t-1}^{i}$. The change in the 9-month-ahead implied forward 3month rate is $\Delta_{270} r_{360, t}^{i}={ }_{270} r_{360, t+1}^{i}-{ }_{270} r_{360, t-1}^{i}$, and so on for the other own rates and expected inflation rates. We calculate the average change in the implied forward commodity own rate for the bundle as $\Delta_{k} r_{k+90, t}$ and the average change in expected inflation as $\Delta_{k} b_{k+90, t+1}{ }^{6}$ We also calculate the aggregate commodity own rates and expected inflation rates as the median commodity change. The median changes are designated with a med superscript. For example, the change in the 9-month-ahead 3-month expected inflation rate from the day before the monetary policy surprise to the day after is given as $\Delta_{270} b_{360, t}^{\text {med }}$.

The volatility of the implied forward T-bill rates, commodity own rates, and commodity expected inflation rates following a monetary policy surprise are shown in Table 2. In the first row, we report summary statistics about the change in the implied forward 3-month T-bill rates following surprises in the federal funds rate. At all four horizons, the standard deviation of the change is 10 or 11 basis points. In the second and third rows we report the volatility of changes in the commodity own rates. As Mishkin (1990) notes, this series is quite volatile relative to inter-

\footnotetext{
6 Cornell and French (1986) weighted the individual commodities by the inverse of measures of volatility in each market. Mishkin (1990) used an unweighted average.
} 
Table 2

Volatility of Changes in Rates Following Federal Funds Rate Surprises

\begin{tabular}{|c|c|c|c|c|}
\hline & 0 to 3 months & 3 to 6 months & 6 to 9 months & 9 to 12 months \\
\hline Implied forward T-bill rates & 10 & 11 & 11 & 11 \\
\hline \multicolumn{5}{|l|}{ Commodity own rates } \\
\hline Mean commodity & 94 & 58 & 43 & 58 \\
\hline Median commodity & 46 & 24 & 19 & 23 \\
\hline \multicolumn{5}{|l|}{ Commodity inflation rates } \\
\hline Mean commodity & 94 & 57 & 42 & 55 \\
\hline Median commodity & 46 & 24 & 18 & 19 \\
\hline
\end{tabular}

est rates: The standard deviation of changes following surprises in the federal funds rate ranges from a high of 94 basis points in the near term to 43 basis points for the implied own rate in the 6to 9-month horizon. In every case, the standard deviations of the median changes are less than half the standard deviations of the mean changes. Here we find that the standard deviations of changes in commodity own rates ranged from 46 basis points in the near horizon to 19 points for the implied own rates in the 6- to 9-month horizon.

The fourth and fifth rows report the standard deviations of the commodity expected inflation rates. Here the volatility pattern is very similar to the pattern for the own rates. The standard deviation of changes following surprises in the federal funds rate ranges from a high of 94 basis points in the near term to 42 basis points for the implied own rate in the 6- to 9-month horizon. Also, the standard deviations of the median changes are less than half the standard deviations of the mean changes. Here we find that the standard deviations of changes in commodity expected inflation rates ranged from 46 basis points in the near horizon to 18 points for the implied own rate in the 6- to 9-month horizon.

\section{RESULTS}

We run simple regressions relating changes in the mean and median commodity own rates to surprises in the policy action. The rationale for this model is simply that at the moment before the policy change, market prices reflect all the information that is relevant, including expectations about policy. The relationship between changes in the mean and median own rates and the policy surprise is measured using the following regressions:

$$
\begin{aligned}
& \Delta_{k} r_{k+90, t}=\alpha_{1}^{r}+\beta_{1}^{r} \Delta f f f_{t}^{h}+\varepsilon_{1, t}^{r} \text { and } \\
& \Delta_{k} r_{k+90, t}^{\text {med }}=\alpha_{2}^{r}+\beta_{2}^{r} \Delta f f f_{t}^{h}+\varepsilon_{2, t}^{r},
\end{aligned}
$$

for $k=0,90,180$, and 270. Similar regressions are used to measure the response of the mean and median commodity expected inflation rates to a monetary policy surprise:

$$
\begin{aligned}
& \Delta_{k} b_{k+90, t}=\alpha_{1}^{b}+\beta_{1}^{b} \Delta f f f_{t}^{b}+\varepsilon_{1, t}^{b} \text { and } \\
& \Delta_{k} b_{k+90, t}^{\text {med }}=\alpha_{2}^{b}+\beta_{2}^{b} \Delta f f f_{t}^{h}+\varepsilon_{2, t}^{b} .
\end{aligned}
$$

The estimation results for these equations are reported in Table 3. The important effect of idiosyncratic shocks results in very low $\mathrm{R}^{2} \mathrm{~s}$ for the regression of the commodity own rates and expected inflation rates on the federal funds surprise. ${ }^{7}$ In the top half we see that in no case is the

7 Poole, Rasche, and Thornton (2002) note that the surprise in the federal funds target is measured with error, leading to biased estimates of the coefficient on the federal funds surprise. The measurement error biases the coefficient toward zero. They show that the variance of the measurement error is small and is unlikely to affect the qualitative nature of our results. 
Table 3

\section{Regressions of Commodity Own Rates and Basis Changes on the Unexpected Component of Federal Funds Announcements}

\begin{tabular}{lcccc} 
& $\beta$ & $\boldsymbol{t}$-Statistic & SEE & $\mathbf{R}^{\mathbf{2}}$ \\
\hline Commodity own rates & & & & \\
$\Delta_{0} r_{90, t+1}$ & -0.65 & -0.62 & 0.96 & 0.00 \\
$\Delta_{0} r_{90, t+1}^{m e d}$ & -0.40 & -0.78 & 0.46 & 0.01 \\
$\Delta_{90} r_{180, t+1}$ & -0.03 & -0.04 & 0.54 & 0.00 \\
$\Delta_{90} r_{180, t+1}^{m e d}$ & 0.18 & 0.68 & 0.24 & 0.01 \\
$\Delta_{180} r_{270, t+1}$ & -0.41 & -0.96 & 0.40 & 0.01 \\
$\Delta_{180} r_{270, t+1}^{m} d$ & 0.02 & 0.08 & 0.18 & 0.00 \\
$\Delta_{270} r_{360, t+1}^{m}$ & 1.25 & 0.54 & 0.02 \\
$\Delta_{270} r_{360, t+1}^{m e d}$ & 1.23 & 0.21 & 0.02 \\
Commodity inflation rates & 0.73 & & & \\
$\Delta_{0} b_{90, t+1}$ & 0.29 & 1.31 & 0.95 & 0.02 \\
$\Delta_{0} b_{90, t+1}^{m e d}$ & & $\mathbf{2 . 2 3}$ & 0.45 & 0.06 \\
$\Delta_{90} b_{180, t+1}$ & 1.36 & 1.38 & 0.52 & 0.06 \\
$\Delta_{90} b_{180, t+1}^{m e d}$ & 1.10 & $\mathbf{2 . 2 8}$ & 0.23 & 0.07 \\
$\Delta_{180} b_{270, t+1}$ & 0.79 & $\mathbf{2 . 6 1}$ & 0.39 & 0.15 \\
$\Delta_{180} b_{270, t+1}^{m e d}$ & 0.58 & $\mathbf{3 . 8 4}$ & 0.16 & 0.00 \\
$\Delta_{270} b_{360, t+1}$ & 1.11 & -0.22 & 0.51 & 0.03 \\
$\Delta_{270} b_{360, t+1}^{m e d}$ & 0.68 & 1.63 & 0.18 &
\end{tabular}

NOTE: Bold indicates that the $t$-statistic is significant at the 5 percent critical level. SEE is the standard error of the equation.

response of the own rate significantly different from zero. At the 9- to 12-month horizon, the response of the real rate is positive and relatively large, but not statistically significant.

The bottom half reports the results for the commodity price expected inflation. The results for the mean response are not significant except in the case of the implied 3-month expected inflation rate from 6 to 9 months. We get significant results more often when we use the median response. Mishkin (1990) argued that the Cornell and French results are unreliable indicators of real interest rate behavior because commodity market returns are so highly variable relative to expected inflation and nominal interest rates that there is little signal about real interest rates in the data. We reduce volatility by using the median response measure, which increases reliability in the significance of our results.
Using the median measure of commodity price expected inflation, we find that expected inflation responded positively and significantly to surprises in the federal funds target for the first three horizons. Only in the case of the 9- to 12month rate is the response not statistically significant at the 5 percent level. Relative to the mean price or own rate, the median appears to effectively filter a substantial amount of idiosyncratic noise from the commodity futures data.

\section{DISCUSSION}

The results in Table 2 appear to be at odds with Gürkaynak, Sack, and Swanson (2003) and Kliesen and Schmid (2004a), who report that inflation expectations decline when there is a surprise increase in the federal funds target. The different results, however, refer to different points on the 
term structure. We find that the positive impact is largest at the 3-month horizon and is not statistically significant at the 1-year horizon.

It is also quite possible that the high-frequency response of commodity prices is not the same as the response of prices across the broad spectrum of goods in the economy. However, Gorton and Rouwenhorst (2004) use monthly data to show that nominal commodity returns are highly and positively correlated with CPI inflation, both its expected and unexpected components.

Our results appear to be at odds with conventional wisdom as well, which suggests that inflation responds to policy actions only after a long lag. The conventional view implies that the immediate response of interest rates to a monetary policy shock is by the real component. Recent developments in macroeconomic theory focus on policy in general equilibrium models. To capture this conventional wisdom, economists have used New Keynesian models that incorporate some form of price stickiness. ${ }^{8}$ Gavin, Keen, and Pakko (2004) analyze the effects of monetary policy shocks in such a model where Calvo-style pricing means that prices change on average once per year and the central bank uses an interest rate rule to implement policy. Within this framework, there is an important difference in the effect of a shock to the interest rate depending on whether the shock is perceived to be temporary or persistent. ${ }^{9}$ Transitory policy shocks affect both expected inflation and the real interest rate. With a transitory shock, the federal funds rate returns to its original level within a few quarters and the implied future short-term rate is essentially unaffected by the shock at the 4-quarter horizon.

However, if the shock is persistent-that is, the market expects that a change in the federal funds target is likely to be fairly permanent-then the effect of a positive shock on the implied future short-term rate may be positive for many quarters. But almost all the effect is due to higher expected

${ }^{8}$ See Woodford (2003, Chap. 3) for a comprehensive analysis of the New Keynesian model.

9 In that model the shocks follow an AR(1) process. The transitory shock has an $\mathrm{AR}(1)$ parameter equal to 0.3 and the persistent shock has a parameter value of 0.95 . inflation. The predicted real interest rate effects of a persistent shock to the federal funds rate target are an order of magnitude smaller than are the effects following a transitory shock. That is, stateof-the-art macroeconomic theory predicts that the real interest rate will not respond to federal funds rate target shocks that are highly persistent.

It is important to understand, then, whether monetary policy shocks are perceived as relatively transitory or relatively permanent. Many empirical studies find that the level of the federal funds rate behaves as if it has a random walk component. Using the futures market data to derive the shocks as we do, Faust, Swanson, and Wright (2004) report that shocks to the change in the federal funds rate are highly persistent.

In the top panel of Table 4, we report the response of the term structure of implied future 3-month T-bill rates to surprises in monetary policy. These coefficients were calculated by regressing the change in the implied forward Tbill rates on the monetary policy surprises in the following regression:

$$
\Delta_{k} \operatorname{Tbill}_{k+90, t}=\alpha_{1}+\beta_{1} \Delta f f f_{t}^{h}+\varepsilon_{1, t},
$$

where $\Delta_{k}$ Tbill $_{k+90, t}$ is the change in the implied forward T-bill rate for values of $k$ equal to 0,90 , 180 , and 270 . We find that for the first four quarters, the response in the implied forward T-bill rate is fairly equal across the term structure from 3 months to 12 months. A 10-basis-point surprise in the federal funds rate leads to a 7-basis-point rise in the 3-month rate and to a pattern of 8-, 7-, and 6-basis-point increases in the implied future 3 -month rates at horizons ending in 6, 9, and 12 months, respectively. In the bottom panel, we report similar regressions in which the dependent variables are changes in the Treasury bill rates, $\Delta_{0}$ Tbill $_{k+90, t}$, maturing in $k+90$ days. The regression is given as

$$
\Delta_{0} \operatorname{Tbill}_{k+90, t}=\alpha_{2}+\beta_{2} \Delta f \int f_{t}^{h}+\varepsilon_{2, t} .
$$

The results show that the 12-month rate changes by only very slightly less than the 3-month rate.

Markets appear to expect that a shock to the federal funds target is relatively permanent-at least that it persists intact for the first year. Accord- 
Table 4

Response of T-Bill Rates to Federal Funds Target Surprises

\begin{tabular}{lcccc} 
Maturity & $\beta$ & $\boldsymbol{t}$-Statistic & SEE & $\mathbf{R}^{\mathbf{2}}$ \\
\hline Implied forward rates & & & & \\
$\Delta_{0}$ Tbill $_{90, t+1}$ & 0.71 & $\mathbf{9 . 8 9}$ & 0.07 & 0.54 \\
$\Delta_{90}$ Tbill $_{180, t+1}$ & 0.77 & $\mathbf{9 . 7 5}$ & 0.07 & 0.53 \\
$\Delta_{180}$ Tbill $_{270, t+1}$ & 0.69 & $\mathbf{7 . 6 1}$ & 0.08 & 0.41 \\
$\Delta_{270}$ Tbill $_{360, t+1}$ & 0.61 & $\mathbf{5 . 8 9}$ & 0.09 & 0.29 \\
T-bill rates & & & & \\
$\Delta_{0}$ Tbill $_{90, t+1}$ & 0.71 & $\mathbf{9 . 8 9}$ & 0.07 & 0.53 \\
$\Delta_{90}$ Tbill $_{180, t+1}$ & 0.73 & $\mathbf{1 1 . 0 4}$ & 0.06 & 0.58 \\
$\Delta_{180}$ Tbill $_{270, t+1}$ & 0.73 & $\mathbf{1 0 . 5 1}$ & 0.06 & 0.56 \\
$\Delta_{270}$ Tbill $_{360, t+1}$ & 0.69 & $\mathbf{9 . 1 2}$ & 0.07 & 0.49
\end{tabular}

NOTE: Bold indicates that the $t$-statistic is significant at the 5 percent critical level. SEE is the standard error of the equation.

ing to general equilibrium macro theory, the shock to the federal funds rate should have significant effects on expected inflation, but not on real interest rates, which is what we see in the commodity futures market.

\section{CONCLUSION}

Although the commodity futures data contain a substantial amount of idiosyncratic noise, they remain an important source of information about how markets respond to the implementation of monetary policy. Evidence presented in this paper shows that real rates of return in commodity markets do not appear to react to surprises in the federal funds target. This result complements research showing that real rates in the long-term market for inflation-protected Treasury securities also do not respond to these surprises. This is also the result predicted by New Keynesian macroeconomic models if the shocks to the federal funds target appear to be persistent. Persistent shocks lead to a significant (almost one-for-one) response by expected inflation but no measurable response by the real interest rate.

Our results show that despite the relative noise in commodity futures markets, the commodity expected inflation rate does respond significantly to surprises in the federal funds rate. The result is consistent with modern theory, but not with conventional wisdom. Conventional wisdom suggests that expected inflation does not respond immediately, but only with a long lag-and the response should be negative, as was found in the long-term indexed bond market. Gürkaynak, Sack, and Swanson (2003) and Kliesen and Schmid (2004a) find that the long-term expected inflation rate falls when there is a surprise increase in the federal funds rate. Our results suggest that the short-term response is different. That is, expected inflation, at least as observed in commodity markets, over the next 3 to 9 months moves in the same direction as a surprise in the federal funds rate target.

\section{REFERENCES}

Clark, Todd E. and Kozicki, Sharon. "Estimating Equilibrium Real Interest Rates in Real Time.” Research Working Paper P04-08, Federal Reserve Bank of Kansas City, September 2004.

Cornell, Bradford and French, Kenneth R. "Commodity Own Rates, Real Interest Rates, and Money Supply Announcements." Journal of Monetary Economics, 1986, 18, pp. 3-20. 
Faust, Jon; Swanson, Eric T. and Wright, Jonathan H. "Identifying VARS Based on High Frequency Futures Data." Journal of Monetary Economics, 2004, 51, pp. 1107-31.

Gavin, William T. and Karamouzis, Nicholas V. "The Reserve Market and the Information Content of M1 Announcements." Federal Reserve Bank of Cleveland Review, 1985, Quarter I, pp. 11-28.

Gavin, William T.; Keen, Benjamin D. and Pakko, Michael R. "The Monetary Instrument Matters." Working Paper 2004-026A, Federal Reserve Bank of St. Louis, November 2004.

Gorton, Gary and Rouwenhorst, K. Geert. "Facts and Fantasies About Commodity Futures." NBER Working Paper 10595, National Bureau of Economic Research, June 2004.

Gürkaynak, Refet S.; Sack, Brian and Swanson, Eric. "The Excess Sensitivity of Long-Term Interest Rates: Evidence and Implications for Macroeconomic Models." Board of Governors of the Federal Reserve System Finance and Economics Discussion Series 2003-50, August 13, 2003.

Kliesen, Kevin L. and Schmid, Frank A. "Monetary Policy Actions, Macroeconomic Data Releases, and Inflation Expectation." Federal Reserve Bank of St. Louis Review, May/June 2004a, 86(3), pp. 9-21.
Kliesen, Kevin L. and Schmid, Frank A. "Do Productivity Growth, Budget Deficits, and Monetary Policy Actions Affect Real Interest Rates? Evidence From Macroeconomic Announcement Data." Working Paper 2004-019A, Federal Reserve Bank of St. Louis, September 2004b.

Kuttner, Kenneth N. "Monetary Policy Surprises and Interest Rates: Evidence from the Federal Funds Futures Market." Journal of Monetary Economics, June 2001, 47(3), pp. 523-44.

Mishkin, Frederic S. "Can Futures Market Data Be Used to Understand the Behavior of Real Interest Rates?” Journal of Finance, March 1990, 45, pp. 245-57.

Poole, William; Rasche, Robert H. and Thornton, Daniel L. "Market Anticipations of Monetary Policy Actions." Federal Reserve Bank of St. Louis Review, July/August 2002, 84(4), pp. 65-93.

Roley, V. Vance and Walsh, Carl E. "Monetary Policy Regimes, Expected Inflation, and the Response of Interest Rates to Money Announcements." Quarterly Journal of Economics, 1985, 100(5, Supplement), pp. 1011-37.

Woodford, Michael. Interest and Prices: Foundations of a Theory of Monetary Policy. Princeton: Princeton University Press, 2003. 
